\title{
Epidemiology set to get fast-track treatment
}

\section{Declan Butler, Paris}

A consortium of leading European research centres and pharmaceutical companies will this week announce a plan to transform epidemiology by combining it with the new techniques of high-throughput biology.

They plan to create a new field of study 'genomic epidemiology' — by using screening technologies derived from the human genome project to chart the molecular, metabolic and disease profiles of thousands of clinical-trial subjects.

The goal is to correlate genetic markers with observations derived from a series of novel biological markers of disease and disease progression, using clinical trials on an epidemiological scale.

The consortium's 10 founding members include the University of Oxford, whose Nuffield Department of Clinical Medicine has access to huge amounts of trial data, and France's National Centre for Genotyping (CNG) near Paris, which specializes in highthroughput genotyping. The European Bioinformatics Institute near Cambridge will provide computing capabilities. Pharmaceutical companies Roche, Novo Nordisk and AstraZeneca are also participating. All data generated will be placed in public-domain databases.

The initial aim of the consortium will be to annotate tissue samples associated with subjects in trials concerning metabolic disorders such as adult-onset diabetes and cardiovascular disease. But the broader goal is to scale up technologies to epidemiological-sized samples, and to create generic tools and protocols that can then be applied to other diseases.

New funding for the multimillion dollar project is still being negotiated, but work can already proceed by redirecting and coordinating funds among the well-resourced participants, says CNG head Mark Lathrop.

A major limitation of current epidemiological studies is their reliance on clinical descriptions of 'disease', advocates of the new approach say. For example, in the 1950s hepatitis was seen as only one disease, albeit with a wide variety of symptoms and epidemiology. Now that the viral mechanism of the condition is understood, it is known that subtypes $\mathrm{A}, \mathrm{B}, \mathrm{C}, \mathrm{D}, \mathrm{E}$ and $\mathrm{F}$ exist and each have very different effects and prognosis.

"Many diseases are in fact a host of different diseases involving different mechanisms, hidden within the same terminology," says John Bell, head of Oxford's clinical medicine department. If certain factors, such as the environment, affect only one subtype, classical epidemiology might not detect that subtype.

The new approach aims to tackle this

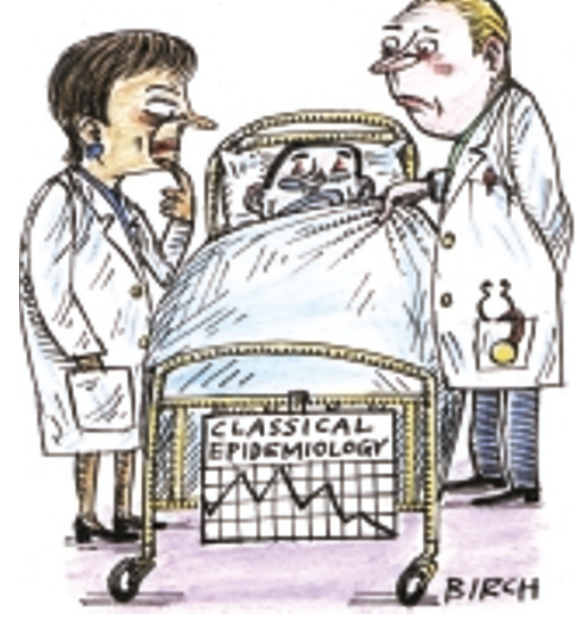

problem by characterizing disease at a systems biology level, using genetics, proteomics, physiology and population biology, says Lathrop. It will collect unprecedented volumes of data on tens of thousands of individuals and store this in shared databases. New tools will be developed to search these for patterns in gene, protein and metabolite data, which will be used to generate hypotheses for further research.

Genetics of disease will form an important aspect of the plan. But the consortium also aims to profile a subject's protein patterns using proteomic screens, and to take a quantitative analysis of every low-molecularweight metabolite in various body fluids, using an emerging technology called 'metabolomics'.

"We think it is important to expand classical epidemiology and genetic epidemiology to take it to this high-throughput mode," says Esper Boel, vice-president of biotechnology research at Novo Nordisk. "We want to use post-genomic technologies to create a new clinical science, to turn functional genomics into real clinical chemistry."

\section{Museums choked by bone law}

Rex Dalton, San Diego

A politically sensitive battle is brewing in California over the repatriation of Native

American skeletal remains held in museums. Scientists say that a state law enacted this month, which requires publicly funded institutions to make items available for claiming by Native American tribes, could deplete their fossil collections.

Passed with little opposition, the law was modelled on a federal statute. But the Californian Native American Graves Protection and Repatriation Act (NAGPRA) gives Native Americans more power in adjudications: tribal representatives will hold seven of the ten positions on a disputeresolving commission. And unlike the federal statute, the state law allows nonfederally recognized tribes to claim remains. California has more than $\mathbf{1 0 0}$ federally recognized tribes and at least 50 others.

The state commission's structure will lead to a "highly politicized" situation, says Phillip Walker, an anthropologist at the University of California, Santa Barbara. The federal body has a balance of scientists and representatives of Native Americans.

State Assemblyman Darryl Steinberg, who introduced the legislation, says it is right to favour Native Americans, because not enough material has been returned so far

Tim White, curator of biological anthropology at Phoebe A. Hearst Museum of Anthropology at the University of California, Berkeley, is worried that questionable claims may succeed. The museum has some $\mathbf{9 , 6 0 0}$ catalogued specimens, many from prehistoric humans. Representatives of tribes who lobbied for the law declined to comment.

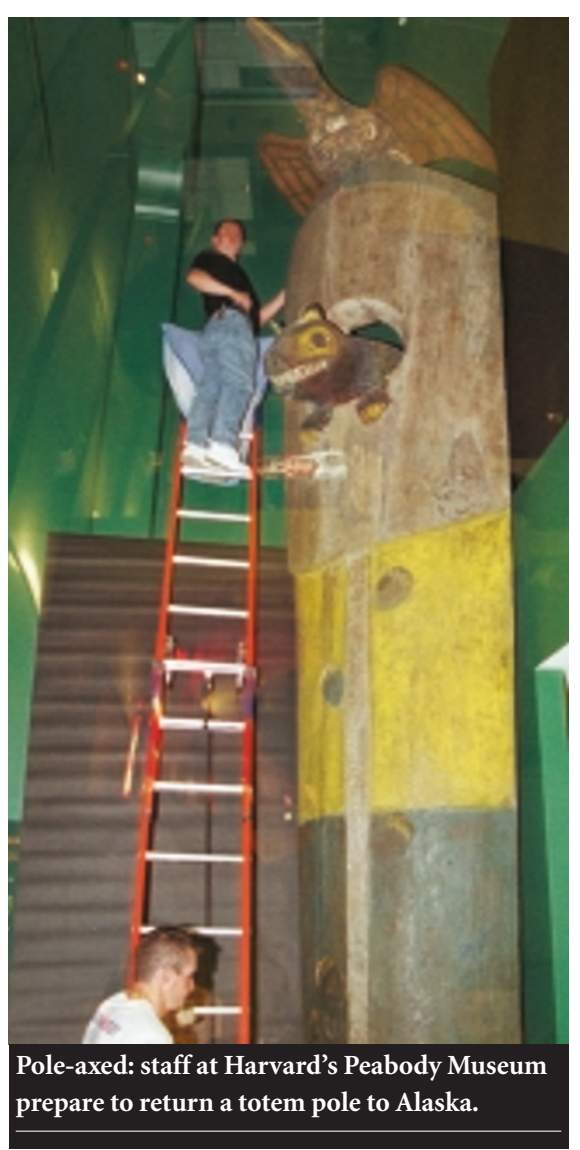

